\title{
Impact of perinatal antibiotic exposure on the infant gut microbiota at one year of age
}

\author{
Ryan Persaud ${ }^{1 *}$, Meghan B Azad ${ }^{2}$, Theodore Konya ${ }^{3}$, David S Guttman ${ }^{4}$, Radha S Chari ${ }^{5}$, Malcolm R Sears ${ }^{6}$, \\ Allan B Becker ${ }^{7}$, James A Scott ${ }^{3}$, Anita L Kozyrskyj ${ }^{2}$, the CHILD Study Investigators ${ }^{8}$ \\ From Canadian Society of Allergy and Clinical Immunology Annual Scientific Meeting 2013 \\ Toronto, Canada. 3-6 October 2013
}

\section{Background}

Disruption of the infant gut microbiota has been linked to long-term health outcomes, including obesity and allergic disease [1]. Antibiotics can significantly alter the microbiota [2], but evidence is scarce for the long-term effect of antibiotic exposure during the perinatal period (shortly before or after delivery). Our research aimed to determine the impact of infant and maternal perinatal antibiotic exposure on the infant gut microbiota at 1 year of age.

\section{Methods}

Antibiotic exposure in the perinatal period was documented by retrospective hospital chart review of 184 Manitoban infants enrolled in the Canadian Healthy Infant Longitudinal Development (CHILD) Study. Data on mode of delivery, indications for treatment, and maternal health status were also collected. Gut microbiota composition (relative abundance of select taxa chosen for their previous association with antibiotic exposure or health outcomes) was determined by Illumina 16S rRNA sequencing of fecal samples collected at 1 year of age. Microbiota diversity was characterized using Chao1 Richness Estimator, Shannon Diversity Index, and Simpson Diversity Index.

\section{Results}

Of the 184 infants, 8 (4.4\%) received intravenous antibiotics during the perinatal period for suspected sepsis. Seventy-two (39.1\%) mothers received antibiotics shortly before or after delivery, resulting in indirect antibiotic exposure of the infant via placental transfer or breast milk. Indirect perinatal antibiotic exposure did not alter

\footnotetext{
* Correspondence: umpersar@cc.umanitoba.ca

'Pharmacy, University of Manitoba, Winnipeg, Manitoba, Canada

Full list of author information is available at the end of the article the 1 year old infant's overall microbiota diversity; however, these infants had an increased relative abundance of Clostridium ( $\mathrm{p}=0.04)$. Infants who were both directly and indirectly exposed to antibiotics had increased microbiota diversity at 1 year of age $(\mathrm{p}<0.03$ for Shannon and Simpson diversity indices computed at Family and Genus levels). These infants also had a lower relative abundance of the phylum Bacteriodetes $(\mathrm{p}=0.03)$, and increased relative abundance of the genus Akkermansia $(\mathrm{p}=0.03)$ and the phylum Proteobacteria $(p=0.02)$. Similar trends were observed following stratification by mode of delivery, premature rupture of membranes, presence of Group B Streptococcus, breastfeeding, and postnatal antibiotics (throughout the first year); except for the decrease in Bacteroidetes, which was attenuated in breastfed infants.

\section{Conclusions}

Antibiotics administered at birth are associated with longlasting changes to the infant gut microbiota, increasing overall diversity and modifying community composition until at least 1 year of age. Maternal perinatal antibiotics may also influence infant gut microbiota composition. Going forward, we will conduct comprehensive microbiota analyses and investigate how antibiotic-associated changes ultimately influence health outcomes during later childhood.

\footnotetext{
Authors' details

${ }^{1}$ Pharmacy, University of Manitoba, Winnipeg, Manitoba, Canada. ${ }^{2}$ Pediatrics, University of Alberta, Edmonton, Alberta, Canada. ${ }^{3}$ Dalla Lana School of Public Health, University of Toronto, Toronto, Ontario, Canada. ${ }^{4}$ Cell \& Systems Biology, University of Toronto, Toronto, Ontario, Canada. ${ }^{5}$ Obstetrics \& Gynecology, University of Alberta, Edmonton, Alberta, Canada. ${ }^{6}$ Department of Medicine, McMaster University, Hamilton, Ontario, Canada. ${ }^{7}$ Pediatrics \& Child Health, University of Manitoba, Winnipeg, Manitoba, Canada. ${ }^{8}$ Canadian Healthy Infant Longitudinal Development Study.
} 


\section{Published: 3 March 2014}

\section{References}

1. Penders J, Thijs C, van den Brandt PA, Kummeling I, Snijders B, Stelma F, Adams H, van Ree R, Stobberingh EE: Gut microbiota composition and development of atopic manifestations in infancy: the KOALA Birth Cohort Study. Gut 2007, 56:661-7.

2. Willing BP, Russell SL, Finlay BB: Shifting the balance: antibiotic effects on host-microbiota mutualism. Nature Reviews Microbiology 2011, 9:233-243.

doi:10.1186/1710-1492-10-S1-A31

Cite this article as: Persaud et al:: Impact of perinatal antibiotic exposure on the infant gut microbiota at one year of age. Allergy, Asthma \& Clinical Immunology 2014 10(Suppl 1):A31.

Submit your next manuscript to BioMed Central and take full advantage of:

- Convenient online submission

- Thorough peer review

- No space constraints or color figure charges

- Immediate publication on acceptance

- Inclusion in PubMed, CAS, Scopus and Google Scholar

- Research which is freely available for redistribution

Submit your manuscript at www.biomedcentral.com/submit 